\title{
Paediatric sedation during upper gastrointestinal endoscopy: Comparison of propofol + ketamine vs sodium thiopental + fentanyl
}

\author{
Alireza Takzare ${ }^{1,2}$, Mehrdad Goudarzi ${ }^{1}$, Anahid Maleki ${ }^{1}$, Alireza Ebrahim Soltani ${ }^{1}$, Fariba Kaheh${ }^{1}$, Sagar Arab ${ }^{1}$, \\ Ebrahim Espahbodi ${ }^{1}$
}

\begin{abstract}
Background: Different drug regimens can be used for management of anxiety before endoscopy. This study aimed to compare the sedation effects of propofol+ketamine (PK) and sodium thiopental+fentanyl (TF) in children during upper gastrointestinal (UGI) endoscopy.

Methods: A triple-blind clinical trial was conducted on 88 children aged 2-12 years who were candidate for UGI endoscopy at Children's Medical Centre, Tehran, Iran, during 2012-2013. It was administered propofol $(2.1 \mathrm{mg} / \mathrm{kg})+$ ketamine $(1 \mathrm{mg} / \mathrm{kg})$ and $100 \%$ oxygen in PK group, and thiopental $(5 \mathrm{mg} / \mathrm{kg})+$ fentanyl $(1 \mathrm{mg} / \mathrm{kg})$ in TF group. The haemodynamic status and degree of sedation by Ramsay's criteria were measured.

Results: The mean age in PK and TF groups was $92.2 \pm 38.2$ and $98.6 \pm 49.5$ months, respectively. The systolic blood pressure and heart rate significantly increased and decreased in PK and TF groups during the procedure, respectively. The frequency of Ramsay's Sedation Scales of 5 and 6 were respectively $72.7 \%$ and $27.3 \%$ for $P F$, and $54.5 \%$ and $45.5 \%$ for TF group ( $p=0.076$ ).

Conclusion: Although both groups were similar in the degree of sedation, PK can be a more appropriate choice for sedation in children with special diseases undergoing endoscopy due to small changes in haemodynamic parameters and, consequently, their higher stability.
\end{abstract}

Keywords: propofol, ketamine, thiopental, fentanyl, esophagogastroduodenoscopy

\section{INTRODUCTION}

Preparation for the endoscopy procedure in children requires full knowledge of physiology and suitable mental state of both the child and the person performing the procedure (1). According to the American Paediatric Academy, preparations for a successful endoscopy entails obtaining a suitable medical history, measuring anaesthesia score from the physical condition, collecting medication history, allergies assessment, age and weight measurements, and assessment of the children's vital signs $(2,3)$. In terms of indications for sedation, according to the instructions of the American Society of Anaesthesiologists, performing general anaesthesia for endoscopy in children should be in fasting condition for four hours before breastfeeding and for six hours before eating solids (2). Almost all the procedures used in gastrointestinal endoscopy should be performed after a medium or deep anaesthesia under careful supervision of an anaesthesiologist (4-6). Many children complain about anxiety before endoscopy, making the procedure complicated (7). There are various methods for solving this problem, such as oral or intranasal midazolam administration in order to facilitate the separation of the child from the mother (8-10). Compared with adults, small and thin air route causes more air flow resistance in children and increases oedema or mucus. In children, tongue fills a higher portion of the air duct compared to adults. This happens mainly in children younger than 3-5 months. These children are also more prone to hyperactive airways after the occurrence upper respiratory tract infections, which make the upper endoscopy in these patients impossible (11). In addition, episodes of hypoxemia occur more often in these children due to their higher oxygen consumption. In this respect, routine administration of oxygen during the endoscopic procedures is an inexpensive way to improve breathing condition and the sedation required for endoscopy in children (12-14).

\footnotetext{
MD, Tehran University of Medical Sciences, Tehran, Iran

Anaesthesiology Department, Children's Hospital Medical Centre, Tehran University of Medical Sciences, Tehran, Iran
}

Correspondence: Alireza Ebrahim Soltani

Anaesthesiology Department, Children's Hospital Medical Centre, Tehran University of Medical Sciences, Tehran, Iran

Received: 1 Feb 2018, Accepted: 8 Apr 2018

E-mail: ezapour.r@sbmu.ac.ir

(C) 2018 by the authors; licensee Modestum Ltd., UK. This article is an open access article distributed under the terms and conditions of the Creative Commons Attribution License (http://creativecommons.org/licenses/by/4.0/). 
Propofol is a phenol derived from hypnotic sedatives. Its effect start fast (less than a minute). It is short-acting and has a quick return. It has anti-nausea, anti-anxiety, sedative and aesthetic effects but does not have analgesic effect. Propofol can be used in children in gastrointestinal procedures (15-17), intensive care (18) and emergencies (19-26). Respiratory depression and sudden apnoea are the major possible side effects of propofol. In general, it has a rapid action combined with a quick return. Ketamine is a synthetic derivative of phencyclidine with palliative and analgesic effects. It is one of analgesic and anaesthetic compounds, but is dose-dependent. Ketamine causes increased heart rate, blood pressure, cardiac output, intracranial pressure and intraocular pressure, while its main problem is laryngospasm. In different countries, low doses of Ketamine are used along with propofol, midazolam and opioid drugs. This combination creates a stable haemodynamic condition and can reduce the side effects associated with anaesthesia (2731). Sodium thiopental is a barbiturate drug and creates anaesthesia by affecting the reticular activating system. It is generally used in short-term anaesthesia. Respiratory system depression and bronchospasm are among its side effects. It also increases heart rate and reduces blood pressure but is short-acting with rapid onset of action (32-34). In general, different drug regimens can be used in the presence of an anaesthesiologist; however, these drugs have side effects such as delay in waking up from anaesthesia, excessive sleepiness, as well as nausea, vomiting, and haemodynamic disorders, which limit the use of these drugs. In this study, the effectiveness of two methods and sedation of two drug combinations of propofol ketamine and Sodium thiopental were examined on sedation in children's upper gastrointestinal endoscopic procedures.

\section{MATERIALS AND METHODS}

This clinical trial study was conducted on 88 children aged two to twelve years candidate for upper gastrointestinal endoscopy at Children's Medical Centre during 2012-2013. The trial was initiated after the approval of the institutional ethic committee review board at Tehran University of Medical Sciences. After obtaining consent from parents, children were divided into two groups with blocks of four based on table of random numbers. It was a triple-blind study. The number of samples in each group was determined as 44 by taking into account an incidence of 0.5 in the first group and 0.2 in the second group, confidence level of 0.5 , and study power of $80 \%$ using STATA. Exclusion criteria included congenital genetic diseases, hypersensitivity to study drugs, abnormal anatomy of the jaw and face, upper respiratory tract infections, behavioural disorders, use of psychiatric drugs, family language other than Persian, and lack of parents' consent. Those who had used hypnotics before arriving the operating room were also excluded. In the first group, after installing the standard monitoring equipment and performing venepuncture, sedation was conducted using a combination of propofol $2.1 \mathrm{mg} / \mathrm{kg}$ and ketamine $1 \mathrm{mg} / \mathrm{kg}$ and administration of one hundred percent oxygen in the endoscopy room. In the second group, thiopental $5 \mathrm{mg} / \mathrm{kg}$ and fentanyl $1 \mathrm{mg} / \mathrm{kg}$ were administered. The haemodynamic variables and degree of sedation of patients were measured in both groups using the Ramsay's criteria and recorded in a data collection chart. If patients needed higher degree of sedation, additional doses of propofol in the first group and thiopental in the second group were administered. Independent t-test was used to compare the quantitative variables. Mann-Whitney test was used in the case of abnormal distribution. Chi-square test or Fisher's exact was used for comparisons between the qualitative variables. SPSS 20 was used for statistical analysis. The significance level was considered less than 0.05 .

\section{RESULTS}

In this study, 44 children were induced with propofol+ketamine, and 44 children were induced with thiopental. The mean age of subjects was $92.2 \pm 38.2$ and $98.6 \pm 49.5$, respectively, while the difference was not significant $(p=0.529)$. In terms of haemodynamic parameters, the mean baseline systolic blood pressure in the group induced with propofol+ketamine was $92.21 \pm 10.17 \mathrm{~mm} \mathrm{Hg}$, which increased to $94.85 \pm 18.58 \mathrm{~mm} \mathrm{Hg}$ during the procedure. In the group induced with thiopental + fentanyl, the mean baseline systolic blood pressure was $93.16 \pm 16.58 \mathrm{~mm} \mathrm{Hg}$, which was reduced to $87.56 \pm 10.29$ during the procedure. The mean heart rate in the propofol+ketamine group was $115.12 \pm 23.36$ per minute, which was increased to $130.02 \pm 13.33$ per minute during the procedure, while in the sodium thiopental + fentanyl group, the mean baseline heart rate was $117.29 \pm 26.10$ per minute, which was reduced to $111.24 \pm 25.29$ per minute during the procedure. The mean respiration rate in the propofol+ketamine group was $31.23 \pm 5.36$ per minute, which reached $31.02 \pm 3.70$ during the procedure, while in the sodium thiopental + fentanyl group, it was $32.32 \pm 3.98$ per minute, which was reduced to $28.82 \pm 8.35$ during the procedure. The mean baseline arterial oxygen saturation in the propofol+ketamine group was $91.31 \pm 8.81$ percent, which reached $95.86 \pm 4.91$ percent during the procedure, while in 
Table 1: Initial characteristics of patients with haemodynamic parameters before and after the intervention

\begin{tabular}{|c|c|c|c|}
\hline parameter & propofol+ketamine $(n=44)$ & sodium thiopental + fentanyl $(n=44)$ & p-value \\
\hline Age (month) & $92.2 \pm 38.2$ & $98.6 \pm 49.5$ & 0.611 \\
\hline Sex (female) & $32(72.7)$ & $34(77.3)$ & 0.323 \\
\hline Weight (kg) & $25.2 \pm 20.9$ & $22.1 \pm 16.2$ & 0.529 \\
\hline \multicolumn{4}{|c|}{ haemodynamic parameters in baseline } \\
\hline systolic blood pressure & $92.21 \pm 10.17$ & $93.16 \pm 16.58$ & 0.747 \\
\hline Heart rate & $115.12 \pm 23.36$ & $117.29 \pm 26.1$ & 0.682 \\
\hline Respiratory rate & $31.23 \pm 5.36$ & $32.32 \pm 3.98$ & 0.282 \\
\hline oxygen saturation & $91.31 \pm 8.81$ & $92.12 \pm 8.34$ & 0.659 \\
\hline \multicolumn{4}{|c|}{ haemodynamic parameters during procedure } \\
\hline systolic blood pressure & $94.85 \pm 18.58$ & $87.56 \pm 10.29$ & 0.025 \\
\hline Heart rate & $130.02 \pm 13.33$ & $111.24 \pm 25.29$ & 0.003 \\
\hline Respiratory rate & $31.02 \pm 3.7$ & $28.82 \pm 8.35$ & 0.042 \\
\hline oxygen saturation & $95.86 \pm 4.91$ & $93.07 \pm 5.84$ & 0.017 \\
\hline
\end{tabular}

Table 2: Complications of sedation after the procedure

\begin{tabular}{|c|c|c|c|}
\hline parameter & propofol+ketamine $(n=44)$ & sodium thiopental + fentanyl $(n=44)$ & p-value \\
\hline Bronchospasm or laryngospasm & $3(6.8)$ & $2(4.5)$ & 0.64 \\
\hline Ramsay score & & & 0.076 \\
\hline 5 & $32(72.7)$ & $24(54.5)$ & \\
\hline 6 & $12(27.3)$ & $20(45.5)$ & \\
\hline Nausea and vomiting & $12(27.3)$ & $14(31.8)$ & 0.644 \\
\hline Nurses' degree of satisfaction & & & 0.268 \\
\hline Very poor & $1(2.3)$ & $1(2.3)$ & \\
\hline Poor & $3(6.8)$ & $4(9.1)$ & \\
\hline Don't Know & $12(27.3)$ & $12(27.3)$ & \\
\hline Good & $18(40.9)$ & $21(47.7)$ & \\
\hline Very good & $10(22.7)$ & $6(13.6)$ & \\
\hline Mean score of satisfaction & $3.57 \pm 0.97$ & $3.61 \pm 0.92$ & 0.5 \\
\hline
\end{tabular}

the sodium thiopental + fentanyl group, the mean baseline arterial oxygen saturation was $92.12 \pm 8.34$ percent, which was reduced to $93.07 \pm 5.84$ percent during the procedure. In evaluation of haemodynamic changes during procedures compared with the baseline values, changes in all indicators between the two groups was significant, so that mild increases in blood pressure, heart rate, respiratory rate and oxygen saturation were observed in the propofol+ketamine group, while all four indicators decreased significantly in the sodium thiopental + fentanyl group (Table 1).

The incidence of bronchospasm or laryngospasm during recovery in the propofol+ketamine group and the sodium thiopental + fentanyl group was $6.8 \%$ and $4.5 \%$, respectively, while the difference between the two groups was not significant ( $p=0.64$ ). The frequency of Ramsay's Sedation Scales of 5 and 6 in the propofol+ketamine group was $72.7 \%$ and $27.3 \%$, respectively, while it was $54.5 \%$ and $45.5 \%$ in the sodium thiopental + fentanyl group, respectively. The difference between the two groups was not significant $(p=0.076)$. The prevalence of nausea and vomiting during the procedure in the propofol+ketamine group was $27.3 \%$, while it was $31.8 \%$ in the sodium thiopental + fentanyl group, and difference was not significant ( $p=0.664$ ). The nurses' degree of satisfaction with the course of recovery was $22.7 \%$ in the propofol+ketamine group and $13.6 \%$ in the sodium thiopental + fentanyl group, while the difference between the two groups was not significant $(p=0.664)$ (Table 2).

\section{DISCUSSION}

This study aimed to compare the outcomes of sedation with propofol+ketamine admixture and thiopental sodium in children undergoing upper gastrointestinal tract endoscopy. In terms of demographic variables (age, sex and weight), there was no statistically significant difference between the two groups. Given the drop in systolic blood pressure and heart rate in the thiopental sodium group and its significance, even though the normal patients did not require specific action and the difference was not clinically significant, and considering the reduction in haemodynamic parameters in this drug class, it seems that thiopental sodium is not a suitable choice in patients undergoing endoscopy with haemodynamic compromise (hypovolemia, gastrointestinal bleeding), and propofol+ketamine admixture is associated with higher cardiovascular stability. Moreover, in terms of oxygen saturation of haemoglobin and respiratory rate, it seems that thiopental sodium is associated with higher incidence of respiratory depression and transient desaturation 
and is not an appropriate choice compared to ketamine+propofol in children's endoscopy procedures, where maintaining spontaneous breathing is especially important. In previous studies, other sedation regimes have been compared. In a study conducted by the Tosun et al., patients were randomly assigned to two groups induced by propofol+ketamine or propofol+fentanyl. Heart rate and respiration rate values were considerably lower in the group receiving fentanyl than the one receiving ketamine. Therefore, even though both groups had appropriate sedation during endoscopy, haemodynamic stability and deeper sedation were observed in the group receiving ketamine (35), which is in agreement with our findings about haemodynamic stability following administration of ketamine. Abu-Shahwan et al. evaluated the effectiveness of propofol+remifentanil admixture administration in deep anaesthesia in children under 7 years undergoing upper gastrointestinal endoscopy. In their study, the propofol+remifentanil admixture led to reduced heart rate, blood pressure and respiratory rate. However, no respiratory depression or oxygen desaturation was observed. Our study suggested that although remifentanil is associated with reduced vital parameters, these changes can be compensated through combining remifentanil with ketamine (36).

In this study, the incidence of coughing was higher in the propofol+ketamine group, but there was no statistically significant difference between the groups which may be attributed to the sample size. Considering the direct association between complications (hypotension, heart rate, respiratory depression and rate, and oxygen saturation of haemoglobin) and sedation score of 6 in the thiopental sodium group, the administered dose seem to be high, and complications are likely to be reduced at a lower dose or at more gradual administration. Nausea and vomiting in the thiopental sodium group was higher compared to the propofol+ketamine group; however, the difference was not statistically significant. It seems that despite the sample size factor, these drugs do not increase the incidence of nausea and vomiting. In terms of mean nurses' score of satisfaction with calmness, the propofol+ketamine group performed better, which was statistically significant. It can be concluded that propofol+ketamine administration results in more satisfaction in terms of calmness in recovery nurses. In a study by Barbi et al., very limited complications was observed in sedation with propofol for upper endoscopy in children, clinically confirming the effectiveness of the drug (37). Burgeat et al. used propofol in combination with sodium thiopental and reported more analgesic consumption at 6 hours after the procedure and higher incidence of nausea and vomiting in the thiopental group (38). In a study by Larrson in the U.S., the group receiving propofol fentanyl experienced higher incidence of bradycardia during surgery, whereas the incidence nausea and vomiting was lower in this group. The period of spontaneous respiration and extubation was lower in the group receiving propofol fentanyl. The apprehension score was also higher in this group compared to the thiopental halothane group, which again indicates the superiority of administration of propofol over thiopental (39). In the study by Motamed in Iran, the effects of oral ketamine and oral fentanyl administration were compared. The required midazolam dose for sedation was lower in the ketamine group. The patients in the ketamine group experienced lower distress levels in IV line insertion and separation from parents for the procedure. Deeper sedation, higher comfort level, and higher endoscopists' satisfaction level were reported in this group. Recovery period was significantly shorter in the ketamine group, which all indicated higher efficiency of ketamine administration compared to other drug regimens (40).

\section{CONCLUSION}

Findings showed that the effects of both drugs used in this study were similar in terms of degree of sedation; however, propofol+ketamine can be a more appropriate choice for sedation in children with special diseases undergoing endoscopy due to small changes in haemodynamic parameters and, consequently, their higher stability.

\section{REFERENCES}

1. Mahajan L, Wyllie R, Steffen R, Kay M, Kitaoka G, Dettorre J, et al. The effects of a psychological preparation program on anxiety in children and adolescents undergoing gastrointestinal endoscopy. J Pediatr Gastroenterol Nutr. 1998;27(2):161-165.

2. Cote CJ, Wilson S, Work Group on S. Guidelines for monitoring and management of pediatric patients during and after sedation for diagnostic and therapeutic procedures: An update. Pediatrics. 2006;118(6):2587-2602. https://doi.org/10.1542/peds.2006-2780

3. Hoffman GM, Nowakowski R, Troshynski TJ, Berens RJ, Weisman SJ. Risk reduction in pediatric procedural sedation by application of an American academy of pediatrics/American society of anesthesiologists process model. Pediatrics. 2002;109(2):236-243. 
4. Hunter A, Mamula P. Bowel preparation for pediatric colonoscopy procedures. J Pediatr Gastroenterol Nutr. 2010;51(3):254-261. https://doi.org/10.1097/MPG.0b013e3181eb6a1c

5. Turner D, Benchimol El, Dunn H, Griffiths AM, Frost K, Scaini V, et al. Pico-salax versus polyethylene glycol for bowel cleanout before colonoscopy in children: A randomized controlled trial. Endoscopy. 2009;41(12):10381045. https://doi.org/10.1055/s-0029-1215333

6. Phatak UP, Johnson S, Husain SZ, Pashankar DS. Two-day bowel preparation with polyethylene glycol 3350 and bisacodyl: A new, safe, and effective regimen for colonoscopy in children. J Pediatr Gastroenterol Nutr. 2011;53(1):71-74. https://doi.org/10.1097/MPG.0b013e318210807a

7. Abbas MI, Nylund CM, Bruch CJ, Nazareno LG, Rogers PL. Prospective evaluation of 1-day polyethylene glycol3350 bowel preparation regimen in children. J Pediatr Gastroenterol Nutr. 2013;56(2):220-224. https://doi.org/10.1097/MPG.0b013e31826630fc

8. Jibaly R, LaChance J, Lecea NA, Ali N, Weber JE. The utility of peg3350 without electrolytes for 2-day colonoscopy preparation in children. Eur J Pediatr Surg. 2011;21(5):318-321. https://doi.org/10.1055/s-0031-1280822

9. Terry NA, Chen-Lim ML, Ely E, Jatla M, Ciavardone D, Esch S, et al. Polyethylene glycol powder solution versus senna for bowel preparation for colonoscopy in children. J Pediatr Gastroenterol Nutr. 2013;56(2):215-219. https://doi.org/10.1097/MPG.0b013e3182633d0a

10. Jimenez-Rivera C, Haas D, Boland M, Barkey JL, Mack DR. Comparison of two common outpatient preparations for colonoscopy in children and youth. Gastroenterol Res Pract. 2009:518932. https://doi.org/10.1155/2009/518932

11. Wexner SD, Beck DE, Baron TH, Fanelli RD, Hyman N, Shen B, et al. A consensus document on bowel preparation before colonoscopy: Prepared by a task force from the American society of colon and rectal surgeons (ascrs), the American society for gastrointestinal endoscopy (asge), and the society of American gastrointestinal and endoscopic surgeons (sages). Gastrointest Endosc. 2006;63(7):894-909. https://doi.org/10.1016/j.gie.2006.03.918

12. Hassall E, Lobe TE. Risks of oral sodium phosphate for pre-colonoscopy bowel preparation in children. Dis Colon Rectum. 2007;50(7):1099-1101. https://doi.org/10.1007/s10350-007-0283-9

13. Wexner SD, Rosen L, Baron TH. Risks of oral sodium phosphate for pre-colonoscopy bowel preparation in children: Response to drs. Hassall and lobe. Surg Endosc. 2007;21(6):1040-1041. https://doi.org/10.1007/s00464007-9397-3

14. Pashankar DS, Uc A, Bishop WP. Polyethylene glycol 3350 without electrolytes: A new safe, effective, and palatable bowel preparation for colonoscopy in children. J Pediatr. 2004;144(3):358-362. https://doi.org/10.1016/j.jpeds.2003.11.033

15. Liacouras CA, Mascarenhas M, Poon C, Wenner WJ. Placebo-controlled trial assessing the use of oral midazolam as a premedication to conscious sedation for pediatric endoscopy. Gastrointest Endosc. 1998;47(6):455-460.

16. Paspatis GA, Charoniti I, Manolaraki M, Vardas E, Papanikolaou N, Anastasiadou A, et al. Synergistic sedation with oral midazolam as a premedication and intravenous propofol versus intravenous propofol alone in upper gastrointestinal endoscopies in children: A prospective, randomized study. J Pediatr Gastroenterol Nutr. 2006;43(2):195-199. https://doi.org/10.1097/01.mpg.0000228099.04702.39

17. Fishbein $M$, Lugo RA, Woodland J, Lininger $B$, Linscheid T. Evaluation of intranasal midazolam in children undergoing esophagogastroduodenoscopy. J Pediatr Gastroenterol Nutr. 1997;25(3):261-266.

18. Thakkar K, El-Serag HB, Mattek N, Gilger MA. Complications of pediatric egd: A 4-year experience in peds-cori. Gastrointest Endosc. 2007;65(2):213-221. https://doi.org/10.1016/j.gie.2006.03.015

19. Tait AR, Malviya S. Anesthesia for the child with an upper respiratory tract infection: Still a dilemma? Anesth Analg. 2005;100(1):59-65. https://doi.org/10.1213/01.ANE.0000139653.53618.91

20. Lightdale JR, Goldmann DA, Feldman HA, Newburg AR, DiNardo JA, Fox VL. Microstream capnography improves patient monitoring during moderate sedation: A randomized, controlled trial. Pediatrics. 2006;117(6):e11701178. https://doi.org/10.1542/peds.2005-1709

21. Gilger MA, Jeiven SD, Barrish JO, McCarroll LR. Oxygen desaturation and cardiac arrhythmias in children during esophagogastroduodenoscopy using conscious sedation. Gastrointest Endosc. 1993;39(3):392-395.

22. Lightdale JR, Valim C, Mahoney LB, Sharon W, DiNardo J, Goldmann DA. Agitation during procedural sedation and analgesia in children. Clin Pediatr (Phila). 2010;49(1):35-42. https://doi.org/10.1177/0009922809344425

23. Schwarz SM, Lightdale JR, Liacouras CA. Sedation and anesthesia in pediatric endoscopy: One size does not fit all. J Pediatr Gastroenterol Nutr. 2007;44(3):295-297. https://doi.org/10.1097/MPG.0b013e31802f6435 
24. Vargo JJ, DeLegge MH, Feld AD, Gerstenberger PD, Kwo PY, Lightdale JR, et al. Multisociety sedation curriculum for gastrointestinal endoscopy. Gastrointest Endosc. 2012;76(1):e1-25. https://doi.org/10.1016/j.gie.2012.03.001

25. Wengrower D, Gozal D, Gozal Y, Meiri C, Golan I, Granot E, et al. Complicated endoscopic pediatric procedures using deep sedation and general anesthesia are safe in the endoscopy suite. Scand J Gastroenterol. 2004;39(3):283-286.

26. Barbi E, Gerarduzzi T, Marchetti F, Neri E, Verucci E, Bruno I, et al. Deep sedation with propofol by nonanesthesiologists: A prospective pediatric experience. Arch Pediatr Adolesc Med. 2003;157(11):1097-1103. https://doi.org/10.1001/archpedi.157.11.1097

27. Amornyotin S, Aanpreung P, Prakarnrattana U, Chalayonnavin W, Chatchawankitkul S, Srikureja W. Experience of intravenous sedation for pediatric gastrointestinal endoscopy in a large tertiary referral center in a developing country. Paediatr Anaesth. 2009;19(8):784-791. https://doi.org/10.1111/j.1460-9592.2009.03063.x

28. Amornyotin S, Aanpreung P. Clinical effectiveness of an anesthesiologist-administered intravenous sedation outside of the main operating room for pediatric upper gastrointestinal endoscopy in thailand. Int J Pediatr. 2010. https://doi.org/10.1155/2010/748564

29. Lowrie L, Weiss AH, Lacombe C. The pediatric sedation unit: A mechanism for pediatric sedation. Pediatrics. 1998;102(3):E30.

30. Bassett KE, Anderson JL, Pribble CG, Guenther E. Propofol for procedural sedation in children in the emergency department. Ann Emerg Med. 2003;42(6):773-782. https://doi.org/10.1016/S019606440300619X

31. Green SM, Krauss B. Propofol in emergency medicine: Pushing the sedation frontier. Ann Emerg Med. 2003;42(6):792-797. https://doi.org/10.1016/S0196064403007467

32. Green SM, Krauss B. The semantics of ketamine. Ann Emerg Med. 2000;36(5):480-482. https://doi.org/10.1067/mem.2000.109510

33. White TJ, 3rd, Siegle RL, Burckart GJ, Ramey DR. Rectal thiopental for sedation of children for computed tomography. J Comput Assist Tomogr. 1979;3(2):286-288.

34. Burckart GJ, White TJ, 3rd, Siegle RL, Jabbour JT, Ramey DR. Rectal thiopental versus an intramuscular cocktail for sedating children before computerized tomography. Am J Hosp Pharm. 1980;37(2):222-224.

35. Tosun Z, Aksu R, Guler G, Esmaoglu A, Akin A, Aslan D, et al. Propofol-ketamine vs propofol-fentanyl for sedation during pediatric upper gastrointestinal endoscopy. Paediatr Anaesth. 2007;17(10):983-988. https://doi.org/10.1111/j.1460-9592.2007.02206.x

36. Abu-Shahwan I, Mack D. Propofol and remifentanil for deep sedation in children undergoing gastrointestinal endoscopy. Paediatr Anaesth. 2007;17(5):460-463. https://doi.org/10.1111/j.1460-9592.2006.02132.x

37. Barbi E, Petaros P, Badina L, Pahor T, Giuseppin I, Biasotto E, et al. Deep sedation with propofol for upper gastrointestinal endoscopy in children, administered by specially trained pediatricians: A prospective case series with emphasis on side effects. Endoscopy. 2006;38(4):368-375. https://doi.org/10.1055/s-2005-921194

38. Borgeat A, Popovic V, Meier D, Schwander D. Comparison of propofol and thiopental/halothane for shortduration ent surgical procedures in children. Anesth Analg. 1990;71(5):511-515.

39. Larsson S, Asgeirsson B, Magnusson J. Propofol-fentanyl anesthesia compared to thiopental-halothane with special reference to recovery and vomiting after pediatric strabismus surgery. Acta Anaesthesiol Scand. 1992;36(2):182-186.

40. Motamed F, Aminpour $Y$, Hashemian $H$, Soltani AE, Najafi M, Farahmand F. Midazolam-ketamine combination for moderate sedation in upper gi endoscopy. J Pediatr Gastroenterol Nutr. 2012;54(3):422-426. https://doi.org/10.1097/MPG.0b013e3182323c75

$\diamond \diamond \diamond \diamond \diamond \diamond \diamond$

http://www.ejgm.co.uk 